\title{
La muerte de un colibrí
}

\author{
Giovanni Peraldo Huertas
}

$\mathrm{E}$ ntonces las mariposas de bellos colores se posaban sobre mí y comenzaban a defecar sobre mi piel que se agrietaba y de las heridas surgían gusanos de colores fosforescentes que me cubrían todo el cuerpo.

- Después... Sí, me acuerdo que después el hedor que despedía el pus que salía de mis heridas olía a rosas y jazmines. ¿Por qué me mira así, doctor?... ¿Piensa, acaso, que estoy loco?

Una pausa mientras el doctor Ospina escribía algo en su libreta de notas, alzaba lentamente su mirada y la posaba en el rostro de su paciente. Un delicado joven adulto de ojos rasgados y mejillas levemente hundidas, cabello castaño caía en bucles sobre los hombros del joven.

\section{—iLoco? ¿Se cree usted loco?}

— ¡No sé, doctor! Es usted quien me está analizando y debería responderme. No yo a usted. ¡Acuérdese de que yo soy el paciente!

Otra pausa en la que el doctor hizo un rápido escrutinio a los cambios en el rostro del joven, le permitió hilvanar sus ideas.
-No lo sé. Fue usted quien mencionó la locura. Yo solo veo a un joven con un terrible terror.

El joven baja la mirada y la posa en los complicados dibujos de la cerámica del piso. Juega con sus manos sudorosas, está entre dubitativo y sereno. Hilvana a su vez su respuesta. La lluvia con un sonido serenamente monótono le sirve para relajarse.

- ¡Es que no sé! Desde mi infancia odié lo bello, pues lo bello generó mi perdición. Pero en fin, doctor, luego me levanté de mi cama y caminé hacia una habitación bellamente pintada con un color naranja que empezó a quemarme mis ojos. Salí corriendo de esa habitación y llegué a un jardín en donde existían grandes esculturas de estilo griego, que representaban jóvenes de rostros y cuerpos bellísimos, pero sus miradas eran de fuego. Me miraban y esa mirada era todo menos que amorosa. Era una mirada que mezclaba odio y lujuria. Grité a todo pulmón pero de repente mi boca se llenaba de pétalos de todo tipo de flores que no me dejaban respirar ni mover mi lengua. Entonces vomité toda una suerte de pétalos y flores pequeñas que al caer al suelo se convirtieron en colibríes de colores que empezaron a 
revolotear a mi alrededor y a causar un ruido infernal y, de vez en cuando, picaban mis brazos desnudos.

En eso el joven se calló y maquinalmente llevó sus manos a sus brazos y los acarició lentamente.

—iY qué más?

—¿Y qué más qué, doctor?

-Quedaste en que los colibríes picaban tus brazos desnudos.

— ¡Cierto! ¡Soy muy distraído! Perdone usted. De un momento a otro estaba en una habitación lujosa en donde ese hombre horrible me acariciaba lentamente la espalda y luego...

—CCómo era ese hombre? ¿Te acuerdas?

-Sí, por supuesto que me acuerdo, era alto, bien parecido, ojos azules claros, mentón partido y nariz respingada.

—Lo recuerdas con lujo de detalles. ¿Por qué motivo?

Una pausa del joven que baja la cabeza y se mira la punta de los tenis.

- iClaro que recuerdo al mal nacido con lujo de detalles!... Era mi padrastro.

El doctor sin inmutarse anotó ese detalle en su libreta de apuntes.

—¿Lo querías?

-No, no lo quería. Bueno, al principio sí, pues se me acercaba con carritos miniatura de los que yo coleccionaba y chocolates. Un día se acercó con la bicicleta que yo deseaba. Inmediatamente la usé y, al entrar a un corredor de la casa, boté una bellísima estatua que ese tipo le regalara a mi progenitora.

El doctor se levanta parsimoniosamente por una taza de café. Se sienta y se queda analizando su bloc de notas.

-Era un tipo abusador, un maldito político que siempre fue un mamador de los puestos públicos que le ofrecían. ¿Cómo va el dicho? ¡Ah, sí! No arrancaba pelos sin sangre. Mi madre estaba enamorada de él. Muy, pero muy enamorada.

Hizo una pausa, tragó saliva mientras organizaba sus pensamientos. El doctor lo observaba relajadamente.

-Pero un día...

El joven deja la frase a medias. Baja la cabeza y está un momento reflexionando.

-Ese día, que si lo miro bien, fue mi liberación de esa casa de mierda... Estaba rodeada de maravillosos jardines y...

-Sí, y de esas bellísimas estatuas, pero ¿qué pasó ese día?

-Sí, claro... ese día... La vida es cruel y pienso que ese día a ella se le rompió el corazón, porque realmente lo amaba... Desgraciadamente amaba el lujo y quien ama el lujo ama el dinero... Nunca lo denunció, pues se llegó a un arreglo legal, si me entiende, un jugoso arreglo monetario. Se puede decir que compró su silencio. 
—Sí, entiendo todo eso, pero siento que evades mi pregunta. ¿Qué pasó ese día?

El joven quedó callado, encarnó su rostro. Miró a todas partes, como repasando la habitación. Luego, clavó sus ojos en los del doctor y se quedó así por un rato, tal vez para enfrentar la pregunta que ya no podía evadir más, para darse valor, quizá. Fue un momento que al doctor le parecieron siglos. Luego el joven bajó la mirada hacia los detalles del piso cerámico, se frotó las manos, posiblemente para evaporar la humedad que iba en aumento, se las pasó por las piernas del pantalón.

—¿Que qué pasó ese día, doctor? Pues que mi madre se enteró de lo que ese maldito me hacía en el jardín cuando ella no estaba. En ese bello jardín, lleno de flores, mariposas, colibríes, esculturas... ¡Era un pervertido! ¿Qué más quiere que le diga? ¿Está claro, o no?

En ese momento sus ojos se anegaron de lágrimas que lo hacían parecer un cachorrito indefenso.

—¿En qué termina tu sueño recurrente?

-En que salgo a todo correr de ese bello jardín y de esa mansión, llego al borde de un precipicio y me lanzo desde él. Cuando voy cayendo los ángeles me observan y se burlan. Otros ángeles desnudos me hacen poses y señas pervertidas y se ríen hasta que se les saltan las lágrimas de unos ojos burlones, sádicos. Yo sigo cayendo y no se ve el término del maldito precipicio. Hasta que caigo en flores y me despierto. ¿Estoy demente, doctor?
-_iEstás paranoico! Es diferente a estar loco.

- Todo lo bello me aterra pero lo feo me ofende. Es una extraña fobia a todo lo bello... Sabe, mi madre era bellísima y manipuladora. Yo que fui la víctima, el perjudicado directo del romance de mi madre con el fulano ese, nunca vi un cinco del famoso arreglo económico por el silencio. Debo reconocer que rentó una casa en donde pasamos juntos una breve temporada, hasta que mi madre se enamoró de otro sujeto millonario, con el que se juntó y salió a vivir a una casa que el sujeto ese tenía por el cerro de la Muerte, creo que se llama Cañón o algo por el estilo. Me dijo que no podía llevarme, por lo que ocurrió antes, que no sabía a ciencia cierta cuáles eran las costumbres del nuevo tipo, pero que era muy tierno. Me imaginé un huevo tierno con mucho dinero. Me dejaría la casa donde vivíamos que ella seguiría rentando para mí. Me depositaba un dinero en mi cuenta, hasta hace poco tiempo en que dejó de hacerlo; entonces, supe que había muerto.

-Pero sigues solo. ¿Has tenido algún tipo de noviazgo?

-En los inicios de mi carrera universitaria conocí a una chica bellísima con la que salí algunas veces. Tuvimos algunas relaciones intensas, pero la empecé a odiar progresivamente porque se parecía a mi madre. Era tan hermosa que terminé por rechazarla. Cuando estábamos juntos me aterraba el solo hecho de sentir su calor, sentir sus caricias en mi desnuda piel. iMe daba vértigo!

-Pero entonces, ¿por qué no buscas una chica menos hermosa? 
—PPorque si me llega a gustar, entonces es porque mi cerebro la percibe hermosa! Empieza, entonces, el ciclo sin fin de mi desdicha, de mi terrible fobia a todo lo bello.

\section{$-Y$, ¿amigos?}

- ¡Sentía lo mismo! Tuve un amigo maravilloso, sensible, pero desgraciadamente hermoso. ¡Hermoso a mi vista! Ojos grandes y rasgados, que me miraban con gran afecto y solo por eso empecé a sacarlo de mi vida, empecé a rechazarlo. Sentía que era mi padrastro que me iba a conducir nuevamente a ese odiado jardín.

- Pero eres bien parecido. ¿Qué ocurre cuando...?

— ¿Cuándo me veo al espejo? ¡Me desprecio! Por eso en mi casa no hay espejos. Mi casa es triste, sombría, gris. Muebles grises y rotos. Nada de cuadros. Eso hace que me sienta mal, triste, cuando estoy en ella. No soporto la fealdad de mi casa, pero la prefiero a una vivienda alegre, llena de colores, llena de cosas bellas. ¡Llena de personas bellas!

El doctor termina su taza de café, se levanta por otra. Ofrece una taza al joven que la acepta y la toma con unas manos finas y delicadas, pero inseguras, temblonas.

—Ten cuidado, está muy caliente... Dime, ¿de qué vives, entonces?

El joven tomó un sorbo de café. Miró al techo, luego miró a través de la ventana. La tarde estaba gris, una tristeza fría invadía la estancia.
-Cuando mi madre murió me dejó una cuantiosa suma de dinero, quizá por arrepentimiento, no lo sé. Quizá ese dinero es parte del famoso arreglo sumado a sus ahorros. Estudié computación. Hago trabajos en mi casa. No vivo mal, si es eso lo que usted cree.

El doctor a su vez ve el techo y se queda así por unos segundos, mientras piensa. Un trueno lejano rompió el silencio de ese instante. Llovía copiosamente, lo que producía un monótono sonido al picar en el techo de hierro del local. De vez en cuando, un vehículo pasaba frente al edificio y rompía la monotonía del murmullo de la lluvia.

El joven nunca sonrió. A veces se le arqueaban los labios en un amago de sonrisa que inmediatamente cambiaba a su estado de seria circunspección.

- ¿Qué pasaría si empiezas a enfrentar tus terrores? Para empezar pon color a tu vivienda, a tu vida. Un cuadro de un jardín estaría perfecto, te ayudaría a enfrentarte en el día a día a tu fobia.

Entonces el joven lo vio con una cara de terror, de espanto mal disimulado; nunca podría hacer tal cosa. Era casi como volver a la terrible mansión de su infancia.

-Doctor, es que no puedo olvidar aquellos momentos en el jardín. Los jadeos en mi oído, aún los puedo percibir. Los colibríes metiendo su duro pico dentro de las campánulas, mientras todas las estatuas las intuía que nos veían y se burlaban con sus rígidas bocas de mármol. Que me observaban y me repudiaban con esos ojos sin vida, vacíos y que sus rostros de piedra 
cambiaban a un rictus de burla... Ya en mi cuarto me quitaba la pantaloneta que quedaban durante los primeros encuentros con ese tono hematita, me bañaba, me restregaba con violencia todo mi cuerpo, tratando de lavar la vileza del momento.

Hubo una pausa que el joven no aprovechó para calmarse, sino que siguió con más desesperación, con voz más alta, casi gritando.

- La semana pasada entró un colibrí en mi casa. Me volví loco del terror. Tomé la escoba y daba golpes al aire como queriendo espantar mis terrores, fue cuando me hice dos heridas en las muñecas y si no hubiera sido por un cliente que entró porque la puerta estaba abierta, me desangraba sin remedio...

— ¿Te quisiste suicidar?

-Fue el intenso temor del momento. Reviví los colibríes introduciendo su pico en las campánulas del jardín... el tono hematita característico de los encuentros... Fue una explosión de todo en mi cansado cerebro... Hace un tiempo traté de suicidarme en la casa. Me encerré en una habitación para morir de inanición, junto con una maldita mariposa; tiré la llave pero la casera entró y me liberó de mi voluntaria prisión; la estúpida pensó que yo estaba desesperado por salir.

Unas lágrimas corrían serenas por las mejillas del joven, y unos ojos desorbitados no atinaban posarse en ningún objeto, vagaban sin sentido por todo el espacio de la habitación y su pecho subía y bajaba en gran agitación.
El doctor, compadecido y abrumado por la explosión que causó con su sugerencia, se acercó y le posó su mano en el hombro pero sintió cómo se tensaba al solo contacto de su mano. Le acarició el cabello y el joven quedó rígido, como esperando un mal, pero luego se fue calmando como un perrillo asustado. Volvía la serenidad en su espíritu. El doctor vuelve a su asiento y anota unas observaciones en su libreta.

-Puedes empezar con poco... no sé... una pequeña flor en la mesa del comedor, pues debes enfrentar tus fobias...

El joven, ya sereno, por primera vez sonrió, una sonrisa cansada, derrotada.

-No sé si lo logre, doctor... creo que sí estoy loco, demente...

El doctor se levanta, toma otra taza de café, ofrece otra al joven que la rechaza con educación. Al llevarse la taza a los labios se percibió un temblor involuntario de su mano.

— ¿Tiembla, doctor? Destruí ese muro de seguridad suyo... el psiquiatra se vuelve loco ante su paciente... ja, ja, ja... Es para una pintura de Dalí...

Se le tornan de color carmesí las mejillas al doctor, deja la taza en la mesita de centro, se arregla la corbata y ofrece una tímida sonrisa al joven.

- iDebes reconocer que estuvo algo intenso el momento!

-Un loco hace ciento como decía Ramón de Campoamor. ¿Ha leído a Campoamor? 
-No soy muy adicto a la literatura. ¿Te gusta la literatura?

-A veces leo. Para pasar el rato.

-Entonces isí te gustan las cosas agradables! ¡La lectura es agradable!

-No lo sé, doctor. La lectura puede acomodarse a los gustos, maniáticos algunos, de los lectores. Cada persona puede hacer su propia lectura de un cuento o de una poesía...

-Talvez. Puede ser cierto lo que dices. En fin, creo que por hoy ha sido suficiente de martirizarte. ¿Te sientes diferente al haber hablado de tus problemas?

- Me siento tranquilo, si es lo que usted deseaba conseguir. ¿Usted está tranquilo, doctor? Creo que no.

El doctor se quedó mirándolo al alejarse el joven del local. Lo vio irse bajo la lluvia, que ya para ese momento era una leve garúa. El joven caminaba rápido, pero con pasos inseguros, a juzgar por lo que movía la cabeza, como si lo persiguiera alguien.

Pasaron los días y el joven no se aparecía por el consultorio del doctor Ospina. No llegó a la siguiente cita, lo cual hizo suponer al doctor que ya no le interesaba o que había mejorado de esa terrible paranoia.
Un día, mientras el doctor veía el noticiario de la tarde, uno de los sucesos del día fue el hallazgo de dos jóvenes desnudos en estado de corrupción dentro de una lúgubre vivienda. Uno de los cuerpos era el de un conocido vagabundo que solía dormir en las aceras bajo los aleros de los negocios. El otro era el dueño de la vivienda, informático de profesión y el nombre era del joven que unos días atrás lo había visitado en su consultorio.

El doctor Ospina se interesó por el caso y decidió visitar la agencia de la policía para informar que ese joven era paciente suyo y que tanto la información que él tenía como la del reporte policial podían servir para integrarlas y dar luz al caso.

En el informe policial se detallaba la macabra escena. Muestra una escena violenta, pues todo estaba revuelto, mesas volcadas, y se menciona un revolver con el que el vagabundo había sido asesinado y el joven se había quitado la vida y estaba a unos centímetros de su mano derecha. El informe concluía que el móvil había sido un crimen pasional. Pero el doctor Ospina no lo creyó, más cuando un detalle le llamó poderosamente la atención. En el informe también se indicaba la presencia de un pequeño colibrí que yacía muerto entre ambos cadáveres. 


\section{Los ojos azules}

Giovanni Peraldo Huertas

L as sirenas de la ambulancia pedían campo a gritos a lo largo de las atascadas calles de la selva de cemento de la ciudad. Dentro de la panza de la ambulancia la mujer inhalaba y exhalaba rítmicamente al compás de los retortijones provocados por las contracciones, mientras que su cara parecía una de esas máscaras que representan la comedia y la tragedia ... obviamente esta última le encajaba de maravilla debido al dramático momento. El hombre con ojos de perro apaleado sostenía la mano izquierda de la mujer con las suyas que se movían cual baile de san Vito y le daba, con una trémula voz, palabras de aliento.

-Sí, ahora decís mi amor, mi tesoro, todo pasará. ¡Tú me hiciste esto!... Infeliz, desgracia... aаaаyyyy...do.

- ¡Peroi mi amor, es una consecuencia del matrimonio!

-Sií, claro, maldito, infeliz, ¡mal naciiiiido! ¡Qué dolor, dios miiiooo!

—Ya, ya, mi tesorito, ya llegamos al nosocomio.

- ¿Y qué putas es un nosocomio? Imbécil, a mí me hablas en cristiano ... Gusano.
-Ya, mi amorcito, ya se te pasará. Luego, luego nos reiremos de este feliz momento.

-Sí, claro. Te reirás tú con tu abuela, desgraciado.

Los paramédicos acostumbrados a estas escenas, quedaban al margen de la discusión y mejor manoseaban el celular.

La camilla en una carrera de campeonato avanzaba con sus llantas como veletas, algunas veces contraponiéndose al movimiento, mientras que sus chillidos de oxidación se mezclaban, en mi menor, con los de la mujer y con el ritmo acompasado de las inhalaciones y exhalaciones. El hombre de ojos de perro apaleado seguía sosteniendo la mano izquierda de la mujer, como diciendo presente. El conjunto se completaba con una sarta de médicos y enfermeras vestidas con gabachas azules.

Las puertas de la sala del quirófano se abrieron como fauces hambrientas que engulleron al pintoresco conjunto... y la camilla también.

Después de veinte minutos de labor, de quejidos y de dos o tres desmayos del hombre de ojos de perro apaleado, el médico extrajo la criatura a 
la que sujetó por los pies y le dio con la otra mano la consabida nalgada como el primer castigo que la vida le daba a la criaturita. El chiquillo empezó un concierto de berridos característicos del dolor del nacimiento.

Lo limpiaron y, entonces, enfermeras y médicos se miraron con ojos como platos, observaron a la mujer y después al hombre, y luego se volvieron y se miraron con las caras inundadas de extrañeza, de estupefacción...

El hombre de la mirada de perro apaleado no resistió la tensión del momento, se frotaba las manos, sudaba copiosamente y el corazón le latía a mil por hora.

— ¿Está bien la criatura? ¿Qué es? ¿Niño o niña? ¿Está sano? ¿Está...?

La pregunta quedó colgando del silencio del momento.

—Sí... sí... está bien... es niño... está sano... pero bueno, ustedes...

La enfermera ante las incongruencias del médico, le entregó el niño a la madre para que se enteraran por ellos mismos de una... ¿cómo lo dijera para que no suene mal? De una contrariedad, un pequeño detalle ...

El papá con gran curiosidad observó al niño y entonces ocurrió... se puso rojo, miró a la madre que, igualmente sorprendida miraba fijamente al niño.

- ¿Pero quién en la familia tiene los ojos azules? Tú y yo, querida, los tenemos oscuros, muy pero muy oscuros. $\mathrm{Y}$ por lo que recuerdo, ni en tu familia ni en la mía han existido personas con ojos azules.

-Pero, amor, el niño está sano ¿qué estás pensando?

- No pienso nada, pero es muy pero muuuuy raro que un niño salga con color de ojos diferentes a los de sus progenitores ¿o a ti no te parece raro, cariñito?

-Calma, calma, señor, ¡no hay que alarmarse por este pequeño detalle! Total que hay niños que nacen con el cabello acolochado, diferente al de sus padres, o con rasgos diferentes, completamente diferentes a los de sus progenitores.

-Lo que dice el doctor es cierto. Está eso del gen recesivo que a veces juega bromas como esta.

¡Recesivo ni qué ojo de hacha! Ahora ¡me explicas bien esto, cariñito!

Mientras tanto, el personal médico le daba la razón a los colegas que habían explicado aspectos científicos de suma validez, sin que una mal disimulada sonrisa se adivinara en los regocijados rostros de varios de los ahí presentes, mientras echaban, disimuladamente, una escrutinadora mirada a la encharcada frente del hombre de la antigua mirada de perro apaleado.

Fuera del quirófano, en la sala de espera, ambas familias esperaban ansiosas entrar para dar los parabienes a los dichosos esposos. Ingresan primero los cuatro suegros y se quedan sin habla. No comprendían cómo ocurrió, pero es claro que en ambas familias no han existido personas con ojos azules, por lo menos hasta donde recuerdan. 
Talvez en la colonia. Saben de un atorrante español que llegó a escorar por estos rumbos que fue el artífice de la familia del hombre furibundo, antes de la mirada de perro apaleado, pero lo que nunca nadie informó es el color de los ojos del atorrante ese.

Mientras tanto, la mujer abrazaba a la criaturita y ponía en toda la cara la expresión de yo no fui.

-Y qué con que el niño tenga los ojos azules, o verdes o amarillos, si está completamente sano que es lo importante.

Pero la bola del cuento se regó por toda la sala de espera donde estaba el resto de ambas familias, quienes todos en manada se apresuraron a ingresar al cuarto del quirófano para ver por ellos mismos el chisme ese de los ojos azules.

Mientras tanto, el hombre antiguamente de ojos de perro apaleado y actualmente de ojos de asesino en ciernes repasaba mentalmente los ojos del lechero, del carnicero, del mecánico...¡El mecánico! ¡Esteban! ¡Maldito bien parecido Esteban! ¡Maldito guapo de Esteban! Tiene los ojos azules, el descarado tan guapo.

-Ajá, queridita, con que el guapetón del Esteban. Ese mequetrefe tan guapo satisfizo su dicha sobre las cenizas de la mía, en el sagrado e incólume tálamo pisoteado por ese canalla.
-Pero, iquerido!

— ¡Nada de querido, queridita! En este momento mi corazón cae hecho pedazos, al ser alcanzado por la cruel y blasfema saeta de tu lascivia.

- ¡No te pongas trágico que tampoco es para tanto! Me estás ofendiendo hasta el tuétano; además, ese pedazo de hombre no es mi tipo y tú lo sabes bien.

Entonces, como una explosión de bomba atómica todos los presentes empezaron a hablar a gritos y acusar a mansalva, mientras los suegros en coro dejaban caer tal aguacero de llanto que parecían los temporales de octubre del Caribe. Aquello parecía un mercado en pleno diciembre en donde empezaron a surgir los nombres de hasta conocidos muertos que también tenían los ojos azules.

Un niño que estaba contemplando al recién nacido, se acercó más a él y con una vocecita fina pero intensa preguntó todo extrañado:

-Pero ¿por qué el chiquito tiene solo un ojo?

Silencio absoluto de las familias y del personal médico, y todos al unísono se quedaron observando estupefactos al recién nacido que a su vez los observa, divertido, con su ojo azul ubicado en medio de la frente. 
